$\overline{\bar{x}}$

\title{
2 スイッチ駆動ハイブリッドシステムの安定化*
}

井村 順一 ${ }^{\dagger}$ ·清水 一寿

\section{Stabilization of a Class of 2-Switch-Driven Hybrid Systems*}

\author{
Jun-ichi ImUrA ${ }^{\dagger}$, Kazutoshi SHIMIZU ${ }^{\ddagger}$ and Masami SAEKI ${ }^{\ddagger}$
}

We consider the two cases to address the stabilization problem of a class of multi-modal hybrid systems with binary-switches. In one case it is reduced to the stabilization problem similar to that for the class of usual continuous linear systems under some condition. In the other case, an approach to find a dynamic state feedback controller that renders the closed loop system well-posed as well as globally asymptotically stable at the equiribrium state is proposed.

\section{1.はじめに}

連続ダイナミクスと離散ダイナミクスが混在したハイ ブリッドシステムは，一般に，不連続な常微分方程式に より記述されるために, 複数解や解が存在しないなどの 現象が生じる。このため, ハイブリッドシステムを議論 するうえで, 解の一意性 (well-posedness) 問題を解く ことは基本的な課題である。しかしながら，ハイブリッ ドシステムの最も簡単なクラスの一つである区分的ア ファインシステムの安定化などの研究でさえ, 閉ループ 系の well-posedness を仮定してきた $[1,2]$.

これに対して，筆者らはこれまでバイモードの区分的 アファインシステムに対して well-posedness 条件を導出 し，さらにwell-posedness を保証したうえで安定化する 手法を提案してきた $[3-6]$. 最近では, スイッチ駆動ハイ ブリッドシステムと呼ぶマルチモードの区分的アファイ ンシステムに対して, その well-posedness 条件について いくつかの結果を得てきている $[7,8]$.

これらの延長線上の研究として, 本論文では, 2 スイッ

\footnotetext{
* 原稿受付 2001 年 5 月 31 日

$\dagger$ 東京工業大学 大学院 情報理工学研究科 Graduate School of Information Science and Engineering, Tokyo Institute of Technology; 2-12-1 Oh-Okayama, Meguroku, Tokyo 152-8552, JAPAN

‡広島大学 工学部 Faculty of Engineering, Hiroshima University; 1-4-1 Kagamiyama, Higashi-Hiroshima 7398527, JAPAN
}

Key Words: hybrid systems, switches, well-posedness, piecewise affine systems.
チを含む，すなわち 4 モードのスイッチ駆動ハイブリッ ドシステムに対して, well-posedness 条件を満たし, か つ安定化する手法を提案する．スイッチ駆動ハイブリッ ドシステム，およびその well-posedness について説明し た後, フィードバック well-posednessの観点から, 対象 とするシステムの中で二つのクラスに注目し，おのおの のクラスについて安定化法を提案する. また, 夕ンク系 と着陸系の例により本手法の有効性を検討する。

以下では, $M=\left[M_{i j}\right], x=\left[x_{i}\right]$ は, それぞれ行列 $M$ の第 $(i, j)$ 要素が $M_{i j}$, ベクトル $x$ の第 $i$ 要素が $x_{i}$ であ ることを表すものとする。

\section{2. 制御対象と問題設定}

\section{1 スイッチ駆動ハイブリッドシステム}

スイッチ駆動ハイブリッドシステム [7]の中で, 本論 文では次の 2 スイッチの場合について考える.

$$
\begin{aligned}
\Sigma: \dot{\bar{x}} & =\left(\bar{A}+\delta_{1} \bar{G}_{1} \bar{F}_{1}+\delta_{2} \bar{G}_{2} \bar{F}_{2}\right) \bar{x}+\bar{B} u \\
\delta_{i} & = \begin{cases}0 \text { if } & \bar{S}_{i} \bar{x} \geq 0 \\
1 \text { if } \quad \bar{S}_{i} \bar{x} \leq 0\end{cases}
\end{aligned}
$$

ここで

$$
\begin{aligned}
& \bar{A}=\left[\begin{array}{ll}
A & a \\
0 & 0
\end{array}\right], \bar{B}=\left[\begin{array}{c}
B \\
0
\end{array}\right], \bar{G}_{i}=\left[\begin{array}{c}
G_{i} \\
0
\end{array}\right], \bar{x}=\left[\begin{array}{l}
x \\
1
\end{array}\right], \\
& \bar{S}_{i}=\left[\begin{array}{ll}
S_{i} & s_{i}
\end{array}\right], \bar{F}_{i}=\left[\begin{array}{ll}
F_{i} & f_{i}
\end{array}\right]
\end{aligned}
$$

であり, $x \in R^{n}$ は連続状態, $u \in R^{m}$ は制御入力, $A \in$ $R^{n \times n}, B \in R^{n \times m}, G_{i} \in R^{n \times l}, S_{i} \in R^{1 \times n}, F_{i} \in R^{l \times n}$, $a \in R^{n}, s_{i} \in R, f_{i} \in R^{l}$ であり, $S_{i}=k S_{j}, i \neq j$ を満た 
す定数 $k$ が存在しないものとする． $\delta_{i}$ をスイッチと呼び, $\delta=\left[\delta_{1}, \delta_{2}\right]^{\top} \in\{0,1\}^{2}$ とおく. このとき $\delta$ の值とモード $I \in\{1,2,3,4\}$ を $\delta_{1}+2 \delta_{2}+1=I$ により同一視する。ま た，(2) 式により定まるモード $I$ の状態 $x$ に関する領域 を $\mathcal{C}_{I}$ と記す.

このシステ公の事象遷移ルールは以下のように与えら れるものとする [7].

スイッチベースト遷移ルール: 連続状態 $x(t)$ が少なく とも一つの部分領域 $\bar{S}_{i} \bar{x} \geq(\leq) 0(i=1,2)$ の条件を満た すことができなくなったときに事象生起し，対応するス イッチ $\delta_{i}$ のみ 0 から 1 に（1から 0 に）切り替わる。

ここで, このルールのもとでは, 事象生起時 $(t=T$ と おく）に遷移先のモードが必ず唯一に定まることに注意 されたい，また，時刻 $t=T$ から新しいモードにおいて始 まる解 $x(t)$ がすべての対応する条件 $\bar{S}_{i} \bar{x} \geq(\leq) 0(i=1,2)$ を満たすことができないときは続いて事象が生起し, 対 応するスイッチのみ 0 から 1 に（1 から 0 に）切り替わ る.こうして以後，すべての対応する条件 $\bar{S}_{i} \bar{x} \geq(\leq) 0$ $(i=1,2)$ を満たすまで時刻 $t=T$ で各スイッチが切り替 わる（この間，時間は進まない）。この場合，時間が進 むことなく永久にモードを遷移し続ける現象が生じうる。 これをライブロックと呼ぶ。まとめると，このルールの もとでは解が存在するならば，その一意性は必ず保証さ れるが, ライブロックの存在が問題となる.

\section{2 well-posedness の定義}

(1) 式に㧍いて $u=0$ とした自律系 $\Sigma_{0} に$ 対して wellposedness を次のように定義する.

【定義 1】初期状態 $(I(0), x(0))$ に対して, $x(t)$ が $\left[0, t_{1}\right)$ 上で $x(t)=x(0)+\int_{0}^{t} f(x(\tau)) d \tau \quad(f$ は $u=0$ とし た (1) 式の右辺を表す) を満たし，かつ $\left[0, t_{1}\right)$ 上に事象 生起時刻の左集積点が存在しないならば, $(I(t), x(t))$ を システム $\Sigma_{0}$ の $\left[0, t_{1}\right)$ 上での解と呼ぶ。また，おの扔の の初期状態 $(I(0), x(0)) \in\{1,2,3,4\} \times R^{n}$ に対して, (1) 式の一意解 $(I(t), x(t))$ が区間 $[0, \infty)$ で存在するならば, システム $\Sigma_{0}$ は well-posed であると呼ぶ.

システム $\Sigma_{0}$ の well-posedness 問題では, $\bar{S}_{i} \bar{x}=0$ で の解の存在性や一意性に注目すればよい [3].これにはつ ざの概念が重要な役割を果たす $[3-6]$.

【定義 2】閉集合 $\mathcal{D} \subset R^{n}$ 上で定義されたシステム $\dot{x}=A x+a$ を考える. $A \in R^{n \times n}, a \in R^{n}$ は定数であ

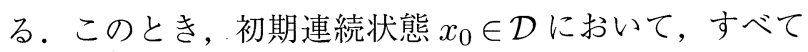
の $t \in[0, \varepsilon]$ に対して $x(t) \in \mathcal{D}$ となる正数 $\varepsilon$ が存在するなら ば， $x_{0}$ はD $\mathcal{D}$ 上で滑らかに接続可能であると呼ぶ．す心゙ ての滑らかに接続可能な初期連続状態 $x_{0}$ の集合を $\mathcal{D} の$ 滑らかな接続集合と呼ぶ.

モード $I$ に対応するシステムに関する， $\mathcal{C}_{I}$ の滑らかな 接続集合を $\mathcal{S}_{I}$ と記すものとすると， $\mathcal{S}_{I}$ は各モードにお ける局所解が存在する領域を表していることに注意され たい。このとき，次の結果が得られている.
【定理 1】[7] 解軌道に事象生起時刻の右集積点が存 在するとき， $I(t)$ はその点で一意に確定できるものとす る。このとき, システム $\Sigma_{0}$ が well-posed であるための 必要十分条件は, $\bigcup_{I=1}^{2_{r}} \mathcal{S}_{I}=R^{n}$ かつ, ライブロックが生 じないことである。

事象生起時刻の右集積点 $t_{\infty}$ では，その時刻以後に解 が一意に発展するために $\left(I\left(t_{\infty}\right), x\left(t_{\infty}\right)\right)$ が一意に確定す る必要がある. $x\left(t_{\infty}\right)$ は常に一意に確定することが示せ る [3]. 一方, $I\left(t_{\infty}\right)$ は現段階では不明であり, 一意に確 定しない例すら得られていない。このため，これ以後は 陽に表記しないが，これを常に仮定するものとする。

滑らかな接続集合 $\mathcal{S}$ はつぎに示すように辞書式不 等式により代数的に特徵づけられる。ここで辞書式不 等式とは, $x=\left[x_{1}, x_{2}, \ldots, x_{n}\right]^{\top} \in R^{n}$ に扔いて,$x_{i}=0$, $i=1,2, \ldots, k-1, x_{k}>0$ であるとき, $x \succ 0$ と記すもの である。また， $x \succ 0$ または $x=0$ のとき, $x \succeq 0$ と記す ものとする.このときシステム $\dot{\bar{x}}=\bar{A} \bar{x}$ の集合 $\mathcal{D}=\{x \in$ $\left.\mathcal{R}^{n} \mid \bar{S} \bar{x} \geq 0\right\}$ での滑らかな接続集合 $\mathcal{S}$ は, $y=\bar{S} \bar{x}$ と扮 くと $\mathcal{S}=\left\{x \mid\left[\begin{array}{llll}y & y^{(1)} & \ldots & y^{(\gamma-1)}\end{array}\right]^{\top} \succeq 0\right\}$, すなわち,

$$
\begin{aligned}
& \mathcal{S}=\left\{x \in R^{n} \mid \bar{T}(\gamma) \bar{x} \succeq 0\right\} \\
& \bar{T}(\gamma) \triangleq\left[\bar{S}^{\top}(\bar{S} \bar{A})^{\top} \ldots\left(\bar{S} \bar{A}^{\gamma-1}\right)^{\top}\right]^{\top}
\end{aligned}
$$

で与えられる。ここに $\gamma$ は対 $(\bar{S}, \bar{A})$ の可観測性指数で ある。

\section{3 問題設定}

(1) 式のシステム $\Sigma$ において, $\bar{B}_{i}(i=1,2, \ldots, m)$ を $\bar{B}$ の第 $i$ 列, $\bar{G}_{j k}\left(j=1,2 ; k=1,2, \ldots, l_{j}\right)$ を $\bar{G}_{j}$ の第 $k$ 列とし, $\bar{F}_{j k}\left(j=1,2 ; k=1,2, \ldots, l_{j}\right)$ を $\bar{F}_{j}$ の第 $k$ 行とす る. $q_{i j}^{k}\left(i, j=1,2 ; k=1,2, \ldots, l_{j}\right)$ を $\left(\bar{S}_{i}, \bar{A}, \bar{G}_{j k}\right)$ の相対次数 $\left(\bar{S}_{i} \bar{A}^{h} \bar{G}_{j k}=0, h=0,1,2, \ldots, q_{i j}^{k}-2\right.$, かつ $\bar{S}_{i} \bar{A}^{q_{i j}^{k}-1} \bar{G}_{j k} \neq$ 0 を満たす）とする。ここで，次の仮定をおく。

(仮定 1)

(i) (1) 式において $a=0, s_{i}>0(i=1,2)$ である.

(ii) $\operatorname{rank} B=m \geq 2$ である.

(iii) $\bar{S}_{i} \bar{A}^{k} \bar{B}_{j}=0\left(i=1,2 ; j=1,2, \ldots, m ; k=1, \ldots, p_{i}-1\right)$ であり, かつ $\operatorname{rank} W=2$ である.ここで

$$
W \triangleq\left[\begin{array}{llll}
\bar{S}_{1} \bar{A}^{p_{1}-1} \bar{B}_{1} & \ldots & \bar{S}_{1} \bar{A}^{p_{1}-1} \bar{B}_{m} \\
\bar{S}_{2} \bar{A}^{p_{2}-1} \bar{B}_{1} & \ldots & \bar{S}_{2} \bar{A}^{p_{2}-1} \bar{B}_{m}
\end{array}\right] \in R^{2 \times m}
$$

である。

(iv) $q_{i j}^{k}<p_{i}$ を満たす $i \in\{1,2\}$ が少なくとも一つ存在す るような $(j, k)$ に対して次式が成り立つ.

$$
\bar{F}_{j k} \in \operatorname{span}\left\{\bar{S}_{1}, \bar{S}_{1} \bar{A}, \ldots, \bar{S}_{1} \bar{A}^{p_{1}-1}, \bar{S}_{2}, \bar{S}_{2} \bar{A}, \ldots, \bar{S}_{2} \bar{A}^{p_{2}-1}\right\}
$$

仮定 1 の (i) は原点 $x=0$ がモード 1 に割り当てられた 領域の内部にあることを仮定している. (ii) は入力数が 2 以上, (iii)の $\left(p_{1}, p_{2}\right)$ は非線形システムにおいてべクト ル相対次数 [9] と呼ばれ, 次章で示すシステムへの変換 を保証するものである（iv)によって不連続要素である 
$\bar{F}_{j k}$ のクラスを限定している.

以上の仮定のもとで，本論文では，次の二つのクラス のシステムに分けて，各モードごとに切り替わる（動的） 状態フィードバックによる，原点での大域的漸近安定化 問題を考える.

クラス $\mathbf{A}$ おのおのの $i \in\{1,2\}$ に対して $p_{i} \leq q_{i j}^{k}, j=$ 1,$2 ; k=1, \ldots, l_{j}$.

クラス $\mathrm{B}$ クラス $\mathrm{A}$ 以外.

\section{3. well-posedness のもとでの安定化}

\section{1 クラス $\mathrm{A}$ の場合}

次式によって与えられる座標変換を考える.

$$
\begin{aligned}
& \xi_{1}=T\left(p_{1}\right) x+\bar{s}_{1} \\
& \xi_{2}=T\left(p_{2}\right) x+\bar{s}_{2} \\
& \eta=S x
\end{aligned}
$$

ここで, $T\left(p_{i}\right) \triangleq\left[S_{i}^{\top},\left(S_{i} A\right)^{\top}, \ldots,\left(S_{i} A^{p_{i}-1}\right)^{\top}\right]^{\top} \in R^{p_{i} \times n}$ であり， $\bar{s}_{i} \triangleq\left[\begin{array}{lll}s_{i} & 0 & \cdots\end{array}\right]^{\top} \in R^{p_{i}}(i=1,2)$ である. $S$ は， $\left[T\left(p_{1}\right)^{\top} T\left(p_{2}\right)^{\top} S^{\top}\right]^{\top}$ が正則で, $S\left[B_{1} B_{2}\right]=0$ を満た すような $\left(n-p_{1}-p_{2}\right) \times n$ の行列である。これは，仮定 1(iii) より $T\left(p_{1}\right)$ と $T\left(p_{2}\right)$ が互いに線形独立である（例 えば [9] 参照）ことからこれらの条件を満たす $S$ が必ず 存在することが導ける．また，以下の入力変換を考える.

$$
\begin{aligned}
& W u+\left[\begin{array}{l}
\bar{S}_{1} \bar{A}^{p_{1}} \bar{x}+\bar{S}_{1} \bar{A}^{p_{1}-1} \sum_{i=1}^{2} \delta_{i} \bar{G}_{i} \bar{F}_{i} \bar{x} \\
\bar{S}_{2} \bar{A}^{p_{2}} \bar{x}+\bar{S}_{2} \bar{A}^{p_{2}-1} \sum_{i=1}^{2} \delta_{i} \bar{G}_{i} \bar{F}_{i} \bar{x}
\end{array}\right]=\left[\begin{array}{l}
v_{1} \\
v_{2}
\end{array}\right] \\
& S B u=\hat{B} v_{3}
\end{aligned}
$$

ここで $v_{i} \in R(i=1,2), v_{3} \in R^{m-2}$ は新しい入力であり, $\hat{B}$ はこの変換で定義された行列である.

これらの変換により(1) 式は以下のようになる。

$$
\tilde{\Sigma}\left\{\begin{array}{c}
{\left[\begin{array}{l}
\dot{\xi_{1}} \\
\dot{\xi_{2}}
\end{array}\right]=\left[\begin{array}{cc}
\tilde{A}_{1} & 0 \\
0 & \tilde{A}_{2}
\end{array}\right]\left[\begin{array}{l}
\xi_{1} \\
\xi_{2}
\end{array}\right]+\left[\begin{array}{cc}
\tilde{B}_{1} & 0 \\
0 & \tilde{B}_{2}
\end{array}\right]\left[\begin{array}{l}
v_{1} \\
v_{2}
\end{array}\right]} \\
\dot{\eta}=\hat{A}_{1}^{I}(\xi-\bar{s})+\hat{\hat{A}}_{2}^{I} \eta+\hat{f}^{I}+\hat{B} v_{3} \quad \text { if } \xi \in \tilde{\mathcal{C}}_{I} \\
I=1, \ldots, 4
\end{array}\right.
$$

ここで, $\xi=\left[\xi_{1}^{\top} \xi_{2}^{\top}\right]^{\top}, \quad \bar{s}=\left[\begin{array}{ll}\bar{s}_{1}^{\top} & \bar{s}_{2}^{\top}\end{array}\right]^{\top}$,

$$
\tilde{A}_{i}=\left[\begin{array}{ccccc}
0 & 1 & 0 & \cdots & 0 \\
\vdots & \ddots & \ddots & \ddots & \vdots \\
\vdots & & \ddots & \ddots & 0 \\
\vdots & & & \ddots & 1 \\
0 & \cdots & \cdots & \cdots & 0
\end{array}\right] \in R^{p_{i} \times p_{i}}, \quad \tilde{B}_{i}=\left[\begin{array}{c}
0 \\
\vdots \\
0 \\
1
\end{array}\right] \in R^{p_{i}}
$$

であり, $\hat{A}_{j}^{I}(j=1,2), \hat{f}^{I}$ は上記の変換で定義された行列 またはべクトルである(ただし $\hat{f}^{1}=0$ となる)。また，こ の変換による $\mathcal{C}_{I}$ を $\tilde{\mathcal{C}}_{I}$ とすると, $\tilde{\mathcal{C}}_{I}=\left\{\xi \in R^{p_{1}+p_{2}} \mid(1\right.$ $\left.\left.2 \delta_{i}\right) \xi_{i, 1} \geq 0, i=1,2\right\}$ であり， $\xi$ みにより表現される.
これより， $\Sigma$ の原点 $x=0$ における安定化問題は，シス テム $\tilde{\Sigma}$ の $\left(\xi_{1}, \xi_{2}, \eta\right)=\left(\bar{s}_{1}, \bar{s}_{2}, 0\right)$ における安定化問題に変 換された. $\tilde{\Sigma}$ が，モードの切替えに直接関係しない $\eta$ の サブシステムと $\left(\xi_{1}, \xi_{2}\right)$ から成る一つの連続システムから 構成されていることに注意すると，次の結果が得られる。

【定理 2】(1) 式のシステムにおいて仮定 1 が成り 立ち， $\left(\hat{A}_{2}^{1}, \hat{B}\right)$ 可安定とする。このとき，入力 $(6)$ 式と， $\tilde{A}_{i}+\tilde{B}_{i} K_{i}$ をフルビッツにする入力 $v_{i}=K_{i}\left(\xi_{i}-\bar{s}_{i}\right)(i=$ $1,2)$ と, モード 1 において $\hat{A}_{2}^{1}+\hat{B} K_{3}$ を安定にする $v_{3}=K_{3} \eta （$ 他のモードの $v_{3}$ は任意に与える）を用いる ならば，閉ループ系は well-posed となり，かつ原点は大 域的漸近安定となる。

(証明） $\tilde{A}_{1} ， \tilde{A}_{2}$ はそれぞれすべてのモードで同じであ り，また切替え則 $x \in \mathcal{C}_{I}$ は， $\left(\xi_{1}, \xi_{2}\right)$ にしか依存しないの で，閉ループ系がwell-posedであることは明らかである。

(7) 式の $\tilde{\Sigma}$ において, $w_{i}=\xi_{i}-\bar{s}_{i}(i=1,2)$ と置き換 えると，閉ループ系は以下のようになる.

$$
\begin{aligned}
& \text { mode1: }\left\{\begin{array}{l}
\dot{w}_{1}=\left(\tilde{A}_{1}+\tilde{B}_{1} K_{1}\right) w_{1} \\
\dot{w}_{2}=\left(\tilde{A}_{2}+\tilde{B}_{2} K_{2}\right) w_{2} \\
\dot{\eta}=\hat{A}_{1}^{1} w+\left(\hat{A}_{2}^{1}+\hat{B} K_{3}\right) \eta
\end{array} \quad \text { if } \xi \in \tilde{\mathcal{C}}_{1}\right. \\
& \text { mode } I:\left\{\begin{array}{l}
\dot{w}_{1}=\left(\tilde{A}_{1}+\tilde{B}_{1} K_{1}\right) w_{1} \\
\dot{w}_{2}=\left(\tilde{A}_{2}+\tilde{B}_{2} K_{2}\right) w_{2} \\
\dot{\eta}=\hat{A}_{1}^{I} w+\hat{A}_{2}^{I} \eta+\hat{f}^{I}+\hat{B} v_{3}
\end{array} \quad \text { if } \xi \in \tilde{\mathcal{C}}_{I}\right.
\end{aligned}
$$

ここで, $I=2, \ldots, 4, w=\left[w_{1}^{\top} w_{2}^{\top}\right]^{\top}$ である.このと き, $\left(\tilde{A}_{i}+\tilde{B}_{i} K_{i}\right)(i=1,2)$ の安定性よりある時刻以後は モード 1 でありつづけるので, $\left(\hat{A}_{2}^{1}+\hat{B} K_{3}\right)$ の安定性よ り, 全系の原点は大域的漸近安定である.

\section{2 クラス $\mathrm{B}$ の場合}

クラスBのシステム (1) 式に対して (5), (6) 式の座標, 入力変換を行うと次のようになる.

$$
\tilde{\Sigma}\left\{\begin{array}{c}
{\left[\begin{array}{c}
\dot{\xi}_{1} \\
\dot{\xi}_{2}
\end{array}\right]=\left[\begin{array}{cc}
\tilde{A}_{1}^{I} & \Gamma_{12}^{I} \\
\Gamma_{21}^{I} & \tilde{A}_{2}^{I}
\end{array}\right]\left[\begin{array}{l}
\xi_{1} \\
\xi_{2}
\end{array}\right]+\left[\begin{array}{cc}
\tilde{B}_{1} & 0 \\
0 & \tilde{B}_{2}
\end{array}\right]\left[\begin{array}{l}
v_{1} \\
v_{2}
\end{array}\right]} \\
\dot{\eta}=\hat{A}_{1}^{I}(\xi-\bar{s})+\hat{A}_{2}^{I} \eta+\hat{f}^{I}+\hat{B} v_{3} \quad \text { if } \xi \in \tilde{\mathcal{C}}_{I} \\
I=1, \ldots, 4
\end{array}\right.
$$

ここで，クラス $\mathrm{A}$ の場合に比べて $\Gamma_{12}^{I}, \Gamma_{21}^{I}$ が加わって いる。ただし， $\Gamma_{12}^{1}=0, \Gamma_{21}^{1}=0, \hat{f}^{1}=0$ であることに 注意されたい.

\subsection{1 準備: well-posedness 条件}

ここでは次節の準備として，モードの切替えに関係す る $\left(\xi_{1}, \xi_{2}\right)$ のサブシステムの well-posedness について, [8] の結果をまとめる. (9) 式において, 入力を $v_{i}=0, i=1,2$ とした次のサブシステムを考える.

$$
\left[\begin{array}{c}
\dot{\xi}_{1} \\
\dot{\xi}_{2}
\end{array}\right]=\left[\begin{array}{cc}
\tilde{A}_{1}^{I} & \Gamma_{12}^{I} \\
\Gamma_{21}^{I} & \tilde{A}_{2}^{I}
\end{array}\right]\left[\begin{array}{l}
\xi_{1} \\
\xi_{2}
\end{array}\right] \quad \text { if } \xi \in \tilde{\mathcal{C}}_{I}
$$

ここで，次の行列の集合を定義する.

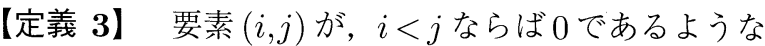


$n \times m$ 実行列の集合を $\mathcal{L}^{n \times m}$ とおく．また，すべての $L_{i i}$ が 0 もしくは正の值である $\mathcal{L}^{n \times m}$ に含まれるすべて の行列の集合をそれぞれ $\mathcal{L}_{0}^{n \times m}, \mathcal{L}_{+}^{n \times m}$ で示す.ささらに， $\mathcal{L}_{0}^{n \times m} \bigcup \mathcal{L}_{+}^{n \times m}$ を $\mathcal{L}_{0 \vee+}^{n \times m}$ で示す.

【定義 4】要素 $(i, j)$ が, $i+1<j$ ならば 0 であるよ うな $n \times m$ 実行列の集合を $\mathcal{H}^{n \times m}$ とおく.また，すべて の $H_{i, i+1}$ が 0 もしくは正の值である $\mathcal{H}^{n \times m}$ に含まれる すべての行列の集合をそれぞれ $\mathcal{H}_{0}^{n \times m}, \mathcal{H}_{+}^{n \times m}$ で示す. さらに, $\mathcal{H}_{0}^{n \times m} \cup \mathcal{H}_{+}^{n \times m}$ を $\mathcal{H}_{0 \vee+}^{n \times m}$ で示す.

以後は, (10) 式が次の仮定を満たすものとする。

(仮定 2) $\tilde{A}_{i}^{I} \in \mathcal{H}_{+}^{p_{i} \times p_{i}}, i=1,2, I=1, \ldots, 4$.

(仮定 3) $\Gamma_{12}^{2}=0, \Gamma_{21}^{3}=0, \Gamma_{21}^{2} \in \mathcal{H}_{0 \vee+}^{p_{2} \times p_{1}}, \Gamma_{12}^{3} \in \mathcal{H}_{0 \vee+}^{p_{1} \times p_{2}}$.

このとき，(10) 式に対する滑らかな接続集合 $\mathcal{S}_{I}$ は次 のように得られる $[8]$.

【補題 1】仮定 2,3 が成り立つとする。このとき, (10) 式に対する滑らかな接続集合 $\mathcal{S}_{I}(I=1, \ldots, 4)$ は次式 で与えられる。

$$
\begin{aligned}
& \mathcal{S}_{1}=\left\{\left(\xi_{1}, \xi_{2}\right) \mid \xi_{1} \succeq 0, \xi_{2} \succeq 0\right\} \\
& \mathcal{S}_{2}=\left\{\left(\xi_{1}, \xi_{2}\right) \mid \xi_{1} \preceq 0, \xi_{2}+M \xi_{1} \succeq 0\right\} \\
& \mathcal{S}_{3}=\left\{\left(\xi_{1}, \xi_{2}\right) \mid \xi_{1}+N \xi_{2} \succeq 0, \xi_{2} \preceq 0\right\} \\
& \mathcal{S}_{2}=\left\{\left(\xi_{1}, \xi_{2}\right) \mid \xi_{1}+\tilde{N} \xi_{2} \preceq 0, \xi_{2}+\tilde{M} \xi_{1} \preceq 0\right\}
\end{aligned}
$$

ここで, $M \in \mathcal{L}_{0 \vee+}^{p_{2} \times p_{1}}, \tilde{M} \in \mathcal{L}_{0 \vee+}^{p_{2} \times p_{1}}, N \in \mathcal{L}_{0 \vee+}^{p_{1} \times p_{2}}, \tilde{N} \in$ $\mathcal{L}_{0 \vee+}^{p_{1} \times p_{2}}$ であり, かつこれらの行列の $(1,1)$ 要素はすべて 0 である。

さらに次の集合を定義する。

【定義 5】行列 $M=\left[M_{i j}\right]$ の $i$ 番目の列ベクトルを $M_{i}$ とおく.このとき, $n \times m$ の実行列 $M=\left[M_{i j}\right]$ にお いて，それぞれの $i \in\{1,2, \ldots, n\} て ゙ ，$ 任意の $\varepsilon_{i} \geq 0$ につ いて $M_{i}-\varepsilon_{i} M_{i+1} \succeq 0$ を満たすならば, $n \times m$ の実行列 $M$ を特殊正下三角行列と呼ぶ.ここで， $M_{n+1}=0$ であ る.この $n \times m$ の特殊正下三角行列の集合を $\mathcal{L}_{s p}^{n \times m}$ と表 記する。また， $\mathcal{L}_{s p}^{n \times m} \bigcap \mathcal{L}_{0}^{n \times m}$.であるすべての行列の集 合を $\mathcal{L}_{s p \wedge 0}^{n \times m}$ と表記する.

このとき

(仮定 4) $M_{i i} N_{i i} \neq 1, \tilde{M}_{i i} \tilde{N}_{i i} \neq 1, i=1,2, \ldots, \min \left\{p_{1}, p_{2}\right\}$ のもとで次の結果を得る。

【定理 3】[8] 仮定 $2 \sim 4$ が成り立つとする.このと き，(10) 式のシステムが well-posed であるための必要 十分条件は, $\tilde{M}-M \in \mathcal{L}_{s p \wedge 0}^{p_{2} \times p_{1}}, \tilde{N}-N \in \mathcal{L}_{s p \wedge 0}^{p_{1} \times p_{2}}$, かつ $I_{p_{2}}-M N \in \mathcal{L}_{+}^{p_{2} \times p_{2}}$ である.ここで, $M, \tilde{M}, N, \tilde{N}$ は (11) 式で与えられる。

\subsection{2 well-posedness のもとでの安定化}

(9) 式の $\tilde{\Sigma}$ の安定化問題は $\left(\xi_{i}-\bar{s}_{i}, \eta\right)=0$ での安定化 であるので, $w_{i}=\xi_{i}-\bar{s}_{i}, i=1,2$ と置き換える. そして, $w_{i}$ の系に対して $v_{i}^{a}, v_{i}^{b}$ を新しい入力として, 次の動的 フィードバックコントローラを考える.

$$
\left\{\begin{array}{l}
\dot{w}_{c i}=v_{i}^{b}, \quad i=1,2 \\
v_{i}=w_{c i}+v_{i}^{a}
\end{array}\right.
$$

このとき，(9) 式を $w_{i}, i=1,2$ で置き換えた式と， 式とで構成される拡大系は以下のようになる。

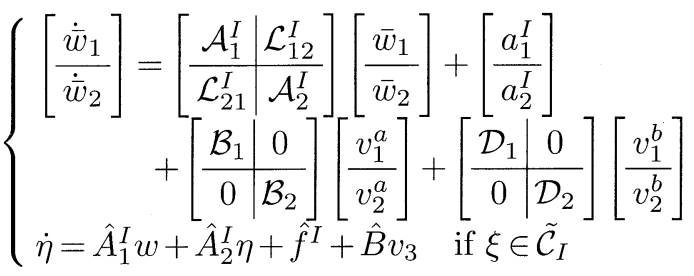

ここで

$$
\begin{aligned}
\mathcal{A}_{i}^{I} & =\left[\begin{array}{cc}
\tilde{A}_{i}^{I} & \tilde{B}_{i} \\
0 & 0
\end{array}\right] \in R^{\left(p_{i}+1\right) \times\left(p_{i}+1\right)} \\
\mathcal{L}_{i j}^{I} & =\left[\begin{array}{cc}
\Gamma_{i j}^{I} & 0 \\
0 & 0
\end{array}\right] \in R^{\left(p_{i}+1\right) \times\left(p_{j}+1\right)} \\
a_{i}^{I}= & {\left[\begin{array}{c}
\tilde{A}_{i}^{I} \bar{s}_{i}+\Gamma_{i j}^{I} \bar{s}_{j} \\
0
\end{array}\right] \in R^{\left(p_{i}+1\right)}, \mathcal{B}_{i}=\left[\begin{array}{c}
\tilde{B}_{i} \\
0
\end{array}\right] \in R^{\left(p_{i}+1\right)} } \\
\mathcal{D}_{i}= & {\left[\begin{array}{lll}
0 & \ldots & 1
\end{array}\right]^{\top} \in R^{\left(p_{i}+1\right)} } \\
& i, j=1,2(i \neq j)
\end{aligned}
$$

であり， $\bar{w}_{i}=\left[\begin{array}{ll}w_{i} & w_{c i}\end{array}\right]^{\top}$ である.また， $I=1$ について， $\Gamma_{12}^{1}=0, \Gamma_{21}^{1}=0, \tilde{A}_{i}^{1} \bar{s}_{i}=0$ であることに注意されたい.

さらに，(13)式の $\left(\bar{w}_{1}, \bar{w}_{2}\right)$ のサブシステムを次のよう にまとめて表す。

$$
\dot{\bar{w}}=\mathcal{A} \bar{w}+a^{I}+\mathcal{B} v^{a}+\mathcal{D} v^{b}
$$

ここで

$$
\begin{aligned}
& \mathcal{A}^{I} \triangleq\left[\begin{array}{c|c}
\mathcal{A}_{1}^{I} & \mathcal{L}_{12}^{I} \\
\hline \mathcal{L}_{21}^{I} & \mathcal{A}_{2}^{I}
\end{array}, \quad a^{I} \triangleq\left[\frac{a_{1}^{I}}{a_{2}^{I}}\right], \quad \bar{w} \triangleq\left[\frac{\bar{w}_{1}}{\bar{w}_{2}}\right],\right. \\
& v^{a} \triangleq\left[\frac{v_{1}^{a}}{v_{2}^{a}}\right], \quad v^{b} \triangleq\left[\frac{v_{1}^{b}}{v_{2}^{b}}\right], \\
& \mathcal{B} \triangleq \operatorname{diag}\left\{\mathcal{B}_{1}, \mathcal{B}_{2}\right\}, \quad \mathcal{D} \triangleq \operatorname{diag}\left\{\mathcal{D}_{1}, \mathcal{D}_{2}\right\}
\end{aligned}
$$

である。ここで, $\operatorname{diag}\left\{A_{1}, A_{2}\right\}$ は行列 $A_{1}, A_{2}$ のブロッ ク対角行列を表す。また， $e_{i}=\left[\begin{array}{llll}1 & 0 & \cdots & 0\end{array}\right] \in R^{1 \times p_{i}}$ を用 いて次の $C_{i}^{I} \in R^{1 \times\left(p_{i}+1\right)}, c_{i}^{I} \in R$ を定義する.

$$
\left[\begin{array}{ll}
C_{i}^{I} & c_{i}^{I}
\end{array}\right]=\left(1-2 \delta_{i}\right)\left[e_{i} s_{i}\right]
$$

このとき，次の結果を得る.

【定理 4】（1）式において仮定 1〜4が成り立ち，クラ ス Bであり, $v_{i}=0, i=1,2$ とした $(9)$ 式の $\xi_{i}$ のサブシ ステムが well-posed であり, $\left(\hat{A}_{2}^{1}, \hat{B}\right)$ 可安定とする.こ のとき, 条件式

$$
\begin{aligned}
& Q=\operatorname{diag}\left\{Q_{1}, Q_{2}\right\}>0, \varepsilon^{I}>0,\left(1-2 \delta_{i}\right) \hat{h}_{i}^{I}>0 \\
& \omega_{i}^{I}>0, \omega_{1}^{I} c_{1}^{I}+\omega_{2}^{I} c_{2}^{I}>0 \\
& L_{1}<0 \\
& {\left[\begin{array}{c|c}
L_{I} & \varepsilon^{I} a^{I}+\mathcal{B} \hat{h}^{I}+\mathcal{D} \hat{k}^{I}-\operatorname{col}\left\{\omega_{i}^{I} Q_{i}\left(C_{i}^{I}\right)^{\top}\right\} \\
\hline * & -2 \varepsilon^{I}\left(\omega_{1}^{I} c_{1}^{I}+\omega_{2}^{I} c_{2}^{I}\right)
\end{array}\right]}
\end{aligned}
$$


$I=2,3,4$

$$
L_{I} \triangleq \mathcal{A}^{I} Q+\mathcal{D} \mathcal{R}^{I}+\left(\mathcal{A}^{I} Q+\mathcal{D} \mathcal{R}^{I}\right)^{\top}
$$

$\left(\operatorname{col}\left\{x_{i}\right\}_{i=1,2}\right.$ は $\left[x_{1} x_{2}\right]^{\top}$ を表す $)$ を満たす, $Q \in R^{(\bar{p}+2) \times(\bar{p}+2)}$ $\left(\bar{p} \triangleq p_{1}+p_{2}\right), \quad \mathcal{R}_{i j}^{I} \in R^{1 \times\left(p_{j}+1\right)}(i, j=1,2), \quad \hat{k}^{I}=\left[\hat{k}_{i}^{I}\right] \in$ $R^{2}, \hat{h}^{I}=\left[\hat{h}_{i}^{I}\right] \in R^{2}, \varepsilon^{I} \in R, \omega^{I}=\left[\omega_{i}^{I}\right] \in R^{2}$ が存在する ならば, 入力 $(6)$ 式と,

$$
\begin{aligned}
& v^{a}= \begin{cases}0 & \text { if } I=1 \\
\hat{h}^{I} \varepsilon^{I^{-1}} & \text { if } I=2,3,4\end{cases} \\
& v^{b}=\left\{\begin{array}{l}
\mathcal{R}^{1} Q^{-1} \bar{w} \quad \text { if } I=1 \\
\mathcal{R}^{I} Q^{-1} \bar{w}+\hat{k}^{I} \varepsilon^{I^{-1}} \text { if } I=2,3,4 \\
K_{3} \eta \text { if } I=1 \quad\left(\hat{A}_{2}^{1}+\hat{B} K_{3}: \text { 安定 }\right) \\
\text { 任意 if } I=2,3,4
\end{array}\right.
\end{aligned}
$$

を組み込んだ (12) 式の動的状態フィードバックコント ローラを用いれば，閉ループ系は well-posed であり，か つ原点 $\left(\xi, w_{c}, \eta\right)=(\bar{s}, 0,0)$ で大域的漸近安定となる.

(証明) まず閉ループ系の well-posedness について示 す. (9) 式の $\xi_{i}$ のサブシステムと (12) 式の動的コント ローラで構成される拡大系で, $v_{i}^{a}=0, v_{i}^{b}=0, i=1,2$ と した場合についてのモード $I$ の滑らかな接続集合 $\mathcal{S}_{I}^{e}$ は, (11) 式の $\xi_{1}, \xi_{2}$ の辞書式不等式に状態 $w_{c i}$ を単に挿入す ることで得られる。こうして，この場合は定理 3 から $\bigcup_{I=1}^{4} \mathcal{S}_{I}^{e}=R^{\bar{p}+2}$ であり, ライブロックは存在しないとい える.さらに (20) 式を組み込んだ $(12)$ 式により構成され る閉ループ系の各モードにおける滑らかな接続集合を $\mathcal{S}_{I}^{c l}$ で表すと, $\hat{h}_{i}^{I}$ の符号の設定により, 各 $I$ について $\mathcal{S}_{I}^{c l} \supseteq \mathcal{S}_{I}^{e}$ が成り立つ。これより閉ループ系において $\bigcup_{I=1}^{4} \mathcal{S}_{I}^{c l}=$ $R^{\bar{p}+2}$ であり，ライブロックは存在しないことが導ける. ゆえに定理 1 より閉ループ系は well-posed である.

つぎに閉ループ系の原点での大域的漸近安定について 示す. (13) 式の $\bar{w}_{i}$ のサブシステムと $(20)$ 式で構成され る閉ループ系

$$
\dot{\bar{w}}=\left(\mathcal{A}^{I}+\mathcal{D} \mathcal{R}^{I} Q^{-1}\right) \bar{w}+\left(a^{I}+\mathcal{B} \frac{h^{I}}{\varepsilon^{I}}+\mathcal{D} \frac{k^{I}}{\varepsilon^{I}}\right)
$$

に対して，次のリアプノフ関数を考える.

$$
V_{I}=\bar{w}^{\top} Q^{-1} \bar{w}+\frac{1}{\varepsilon^{I}}
$$

このとき, 定理の条件式およびS-procedureより, $\dot{V}_{I}(\bar{w})<$ 0 となり $\bar{w}(t)$ は $\bar{w}=0$ に収束することがいえる。こうして ある時刻以後は $I(t)=1$ であり続ける. よって $\hat{A}_{2}^{1}+\hat{B} K_{3}$ の安定性より，全系の原点は大域的漸近安定である。

定理 4 における，(9) 式の $\xi_{i}$ のサブシステムがwellposed であるという条件は，クラス B に対しては閉ルー プ系をフィードバック制御によって well-posedにするた めの必要条件である。また，(16), (19)式の条件式は LMI とはなっていないことに注意されたい. 実際に定理 4 を 用いて設計を行う場合, (17) 式の $\omega_{i}^{I}$ は $\omega_{1}^{I} c_{1}^{I}+\omega_{2}^{I} c_{2}^{I}>0$
となるよう任意の正の值を与えることにより (16)，(18), (19) 式は LMI 形式となるので数值計算により解くこと

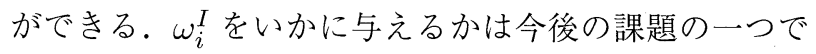
ある。

\section{4. 例}

\section{1 タンク系}

クラス Aの場合の例として Fig. 1のようにバルブとポ ンプがあらかじめ備わったタンク系の安定化を考光る。

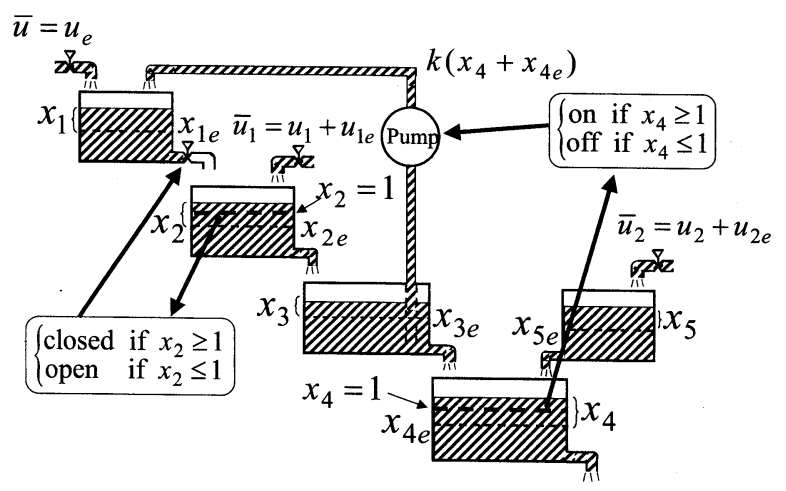

Fig. 1 5-tank system

タンク 1 の下のバルブは Fig. 1 の規則に従って開閉す る.また，ポンプはFig. 1の規則に従い，作動時にはタン ク 3 からタンク 1 へ水を汲み上げる。このシステムの制御 目標は，各タンクの水位を目標值になるように制御する ことである. Fig. 1において, $x_{i}$ は平衡状態 $x_{i e}$ からの変 位, $\bar{u}_{i}$ は蛇口 $i$ から排出された水の量, $u_{i}$ は平衡入力 $u_{i e}$ からの変位を示している. また, $\bar{u}=u_{e}$ は一定である. な お, タンクは十分に深く, バルブ開閉切替え, ポンプ動作 の時間遅れなどはないものとする。ここで, 平衡状態と入 力は $-x_{1 e}+u_{e}=0, x_{1 e}-x_{2 e}+u_{1 e}=0, x_{2 e}-x_{3 e}=0$, $x_{3 e}-x_{4 e}+x_{5 e}=0,-x_{5 e}+u_{2 e}=0, x_{i e}>0, i=1, \ldots, 5$ を満たす。このとき，(1) 式において各行列は次のよう に与えられる。

$$
\begin{aligned}
& \bar{A}=\left[\begin{array}{ccccc|c}
-1 & 0 & 0 & 0 & 0 & 0 \\
1 & -1 & 0 & 0 & 0 & 0 \\
0 & 1 & -1 & 0 & 0 & 0 \\
0 & 0 & 1 & -1 & 1 & 0 \\
0 & 0 & 0 & 0 & -1 & 0 \\
\hline 0 & 0 & 0 & 0 & 0 & 0
\end{array}\right], \bar{B}=\left[\begin{array}{ll}
0 & 0 \\
1 & 0 \\
0 & 0 \\
0 & 0 \\
0 & 1 \\
\hline 0 & 0
\end{array}\right] \\
& \bar{G}_{1}=\left[\begin{array}{cc}
1 & 0 \\
0 & 1 \\
0 & 0 \\
0 & 0 \\
0 & 0 \\
\hline 0 & 0
\end{array}\right], \bar{G}_{2}=\left[\begin{array}{cc}
1 & 0 \\
0 & 0 \\
0 & 1 \\
0 & 0 \\
0 & 0 \\
\hline 0 & 0
\end{array}\right], \quad \bar{F}_{2}=\left[\begin{array}{ccccc|c}
1 & 0 & 0 & 0 & 0 & x_{1 e} \\
-1 & 0 & 0 & 0 & 0 & -x_{1 e}
\end{array}\right],
\end{aligned}
$$

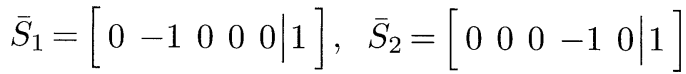

これより，仮定 1 を満たし，かつクラス A の場合である ことが確認できる。(5), (6) 式の座標, 入力変換により, 
(7)式は次式のように与えられる.

$$
\begin{aligned}
& \left\{\begin{array}{l}
\dot{\xi_{1}}=v_{1} \\
\dot{\xi_{2}}=\left[\begin{array}{ll}
0 & 1 \\
0 & 0
\end{array}\right] \xi_{2}+\left[\begin{array}{l}
0 \\
1
\end{array}\right] v_{2}
\end{array}\right. \\
& \left\{\begin{array}{l}
\dot{\eta}=\left[\begin{array}{ccc|cc}
0 & 0 & 0 & -1 & 0 \\
-1 & 0 & 0 & 0 & -1
\end{array}\right]\left[\frac{\xi}{\eta}\right] \begin{array}{c}
\text { if } \xi \in \tilde{\mathcal{C}}_{1} \\
\dot{\eta}=\left[\begin{array}{ccc|cc}
0 & 0 & 0 & 0 & 0 \\
-1 & 0 & 0 & 0 & -1
\end{array}\right]\left[\frac{\xi}{\eta}\right]+\left[\begin{array}{c}
x_{1 e} \\
0
\end{array}\right] \quad \text { if } \xi \in \tilde{\mathcal{C}}_{2} \\
\dot{\eta}=\left[\begin{array}{ccc|cc}
0 & -k & 0 & -1 & 0 \\
-1 & k & 0 & 0 & -1
\end{array}\right]\left[\frac{\xi}{\eta}\right]+\left[\begin{array}{c}
k x_{4 e} \\
-k x_{4 e}
\end{array}\right] \\
\dot{\eta}=\left[\begin{array}{ccc|cc}
0 & -k & 0 & 0 & 0 \\
-1 & k & 0 & 0 & -1
\end{array}\right]\left[\frac{\xi}{\eta}\right]+\left[\begin{array}{c}
x_{1 e}+k x_{4 e} \\
-k x_{4 e}
\end{array}\right] \\
\text { if } \xi \in \tilde{\mathcal{C}}_{4}
\end{array}
\end{array}\right.
\end{aligned}
$$

モード 1 において $\eta$ に関するダイナミクスは安定である ので, 定理 2 を適用でき, 例えば安定化制御則は次のよ うに与えられる。

$$
\begin{aligned}
& v_{1}=-2\left(\xi_{1}-1\right) \\
& v_{2}=\left[\begin{array}{ll}
-1-2
\end{array}\right]\left(\xi_{2}-\left[\begin{array}{l}
1 \\
0
\end{array}\right]\right)
\end{aligned}
$$

制御していない時と，(6), (23) 式による制御入力を印 加した時のシミュレーション結果をそれぞれ Fig. 2(a), (b) に示す。また，制御入力の時間応答を Fig. 2(c) に示 した。このときの各值は $k=0.3, x_{1 e}=0.5, x_{4 e}=1.0$ とし, 初期值は $x(0)=\left[\begin{array}{llllll}8 & 2 & 6 & 2 & 2 & 2\end{array}\right]^{\top}$ とした. 制御し ていない場合の Fig. 2(a)では，バルブが高速で開閉する チャタリングと呼ばれる現象が起こっている。これは害 用上避けるべき現象である。一方，提案則を用いた場合 の Fig. 2(b)では, 滑らかに切り替わり原点に収束してお り，制御入力が有効に働いていることがわかる。このと き，モードの移り変わりは，初期状態がモード4であり， 0.347 秒でモード 3 に移り，3.365秒でモード 1 となった。

\section{2 着陸系}

クラスBの場合の例として, Fig. 3のシステムについて 考える。これは，飛行機のような物体に二つの脚がついた 着陸系の例である。ここで， $\hat{x}_{1}, \hat{x}_{3}$ はそれぞれ系の位置 とし $\hat{x}_{2}, \hat{x}_{4}$ はそれぞれの速度である. $\hat{x}_{5}, \hat{x}_{6}$ はそれぞれ 機体の点 $\mathrm{A}$, 点 $\mathrm{B}$ に働く力であり, これは係数 $\lambda_{1}, \lambda_{2}$ の一 次遅れ要素の駆動系を通じて $u_{1}, u_{2}$ により制御できるも のとする. $k$ はばね係数, $d$ はダンピング係数, $m$ は系の 質量, $I$ は重心まわりの慣性モーメント, $l$ は脚の自然長, $L$ は機体の $A-B$ 間の距離である。また, $u_{1}, u_{2}$ を制御入 力とし, $\alpha=-1 / m-L^{2} /(4 I), \beta=-1 / m+L^{2} /(4 I)$ と する．ここで， $x_{e}, u_{e}(=0)$ をそれぞれ平衡状態と平衡入 力と扔く.また, $2 k\left(l-x_{1 e}\right)=m g, x_{1 e}=x_{3 e}$ に注意する. この場合の制御問題は，系を滑らかな切替えのもとで $x_{e}$

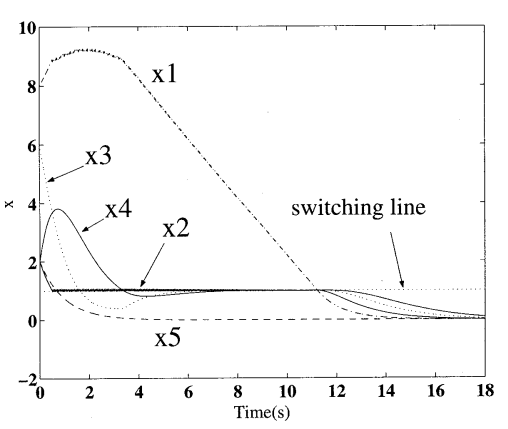

(a) Time response of the state in $u=0$

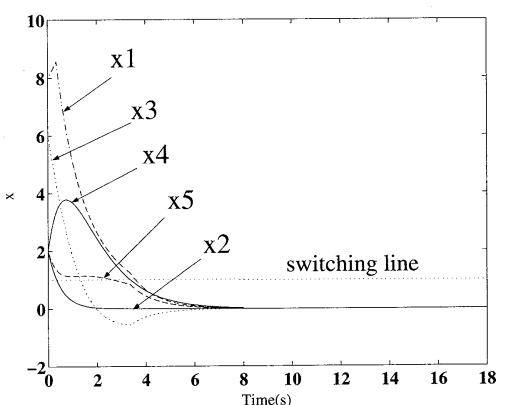

(b) Time response of the state in the proposed method

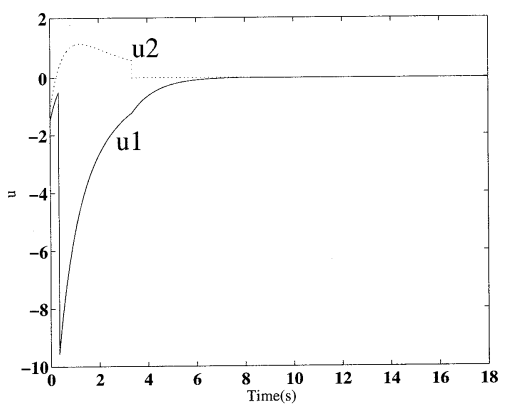

(c) Time response of the control input

Fig. 2 Simulation results of a 5 -tank system

に着陸させることである.ゆえに, $x=\hat{x}-x_{e}, u=\hat{u}-u_{e}$ と扔くと，(1)式の各行列は次のように与えられる.

$$
\begin{aligned}
& \bar{A}=\left[\begin{array}{cccccc|c}
0 & 1 & 0 & 0 & 0 & 0 & 0 \\
\alpha k & \alpha d & \beta k & \beta d & -\alpha & -\beta & 0 \\
0 & 0 & 0 & 1 & 0 & 0 & 0 \\
\beta k & \beta d & \alpha k & \alpha d & -\beta & -\alpha & 0 \\
0 & 0 & 0 & 0 & -\lambda_{1} & 0 & 0 \\
0 & 0 & 0 & 0 & 0 & -\lambda_{2} & 0 \\
\hline 0 & 0 & 0 & 0 & 0 & 0 & 0
\end{array}\right], \\
& \bar{B}=\left[\begin{array}{ll}
0 & 0 \\
0 & 0 \\
0 & 0 \\
0 & 0 \\
1 & 0 \\
0 & 1 \\
\hline 0 & 0
\end{array}\right], \bar{G}_{1}=\left[\begin{array}{c}
0 \\
-\alpha \\
0 \\
-\beta \\
0 \\
0 \\
0
\end{array}\right], \bar{G}_{2}=\left[\begin{array}{c}
0 \\
-\beta \\
0 \\
-\alpha \\
0 \\
0 \\
0
\end{array}\right],
\end{aligned}
$$




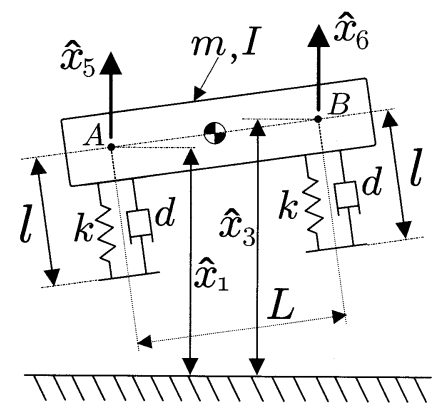

Fig. 32 d.o.f. landing system

$$
\begin{aligned}
& \bar{F}_{1}=\left[\begin{array}{lllllll}
k & d & 0 & 0 & 0 & 0 & k\left(x_{3 e}-l\right)
\end{array}\right], \\
& \bar{F}_{2}=\left[\begin{array}{lllllll}
0 & 0 & k & d & 0 & 0 & k\left(x_{1 e}-l\right)
\end{array}\right], \\
& \bar{S}_{1}=\left[\begin{array}{llllll}
-1 & 0 & 0 & 0 & 0 & 0 \\
& l-x_{1 e}
\end{array}\right] \text {, } \\
& \bar{S}_{2}=\left[\begin{array}{llllll}
0 & 0 & -1 & 0 & 0 & 0
\end{array} \mid-x_{3 e}\right]
\end{aligned}
$$

ここで, $\delta_{1}=0\left(\delta_{2}=0\right)$ のとき脚 $\mathrm{A}(\mathrm{B})$ が地面より離れ， $\delta_{1}=1\left(\delta_{2}=1\right)$ のとき脚 $\mathrm{A}(\mathrm{B})$ が地面に接地しているとし た。これより，仮定 1 を満たし，かつクラス B の場合で あることが示せる. また，(5), (6) 式の座標, 入力変換 により (9) 式の各行列は

$$
\begin{aligned}
& \tilde{A}_{1}^{1}=\tilde{A}_{2}^{1}=\tilde{A}_{2}^{2}=\tilde{A}_{1}^{3}=\left[\begin{array}{lll}
0 & 1 & 0 \\
0 & 0 & 1 \\
0 & 0 & 0
\end{array}\right] \\
& \tilde{A}_{1}^{2}=\tilde{A}_{2}^{3}=\tilde{A}_{1}^{4}=\tilde{A}_{2}^{4}=\left[\begin{array}{ccc}
0 & 1 & 0 \\
-\alpha k & -\alpha d & 1 \\
0 & 0 & 0
\end{array}\right] \\
& \Gamma_{12}^{1}=\Gamma_{21}^{1}=\Gamma_{21}^{2}=\Gamma_{12}^{3}=0 \\
& \Gamma_{21}^{2}=\Gamma_{12}^{3}=\Gamma_{12}^{4}=\Gamma_{21}^{4}=\left[\begin{array}{ccc}
0 & 1 & 0 \\
-\beta k & -\beta d & 1 \\
0 & 0 & 0
\end{array}\right]
\end{aligned}
$$

で与えられる。これより仮定 2,3 を満たす。 さらに， $v_{1}, v_{2}=0$ とした $(9)$ 式のシステムの滑らかな接続集合は (11)式において

$$
M=\tilde{M}=N=\tilde{N}=\left[\begin{array}{ccc}
0 & 0 & 0 \\
0 & 0 & 0 \\
-\beta k & -\beta d & 0
\end{array}\right]
$$

により与えられることがわかるので, 仮定 4 を満たし， かつ定理 3 を満たすことが確認できる。こうして入 力 $v_{1}=v_{2}=0$ のシステムは well-posedである.よって 定理 4 を用いて制御系を設計することができる。そこ で $w_{i}=\xi_{i}-\bar{c}_{i}$ の座標変換を施し，(13) 式のように拡 大系を構成する. 各物理量は $k=55, d=1, m=20$, $l=2, L=5, g=9.8$ と抏いた。これにより, 平衡点 は $x_{1 e}=x_{3 e}=0.2182$ である.また $\lambda_{1}, \lambda_{2}=1$ とした。 さらに (17) 式の $\omega_{i}^{I}$ は, $\omega_{1}^{2}=40, \omega_{2}^{2}=0.1, \omega_{1}^{3}=0.1$, $\omega_{2}^{3}=40, \omega_{1}^{4}=40, \omega_{2}^{4}=40$ と与えた（16)，(18)，(19) 式を解いて得られた制御則は次のと㧍りである.

$$
\begin{aligned}
& \left\{\begin{array}{c}
v^{a}=0 \\
v^{b}=\left[\begin{array}{cccc}
-5603.2 & -1827.5 & -338.9 & -29.0 \\
0 & 0 & 0 & 0 \\
0 & 0 & 0 & 0 \\
-5603.2 & -1827.5 & -338.9 & -29.0
\end{array}\right] \bar{w} \\
\end{array}\right.
\end{aligned}
$$

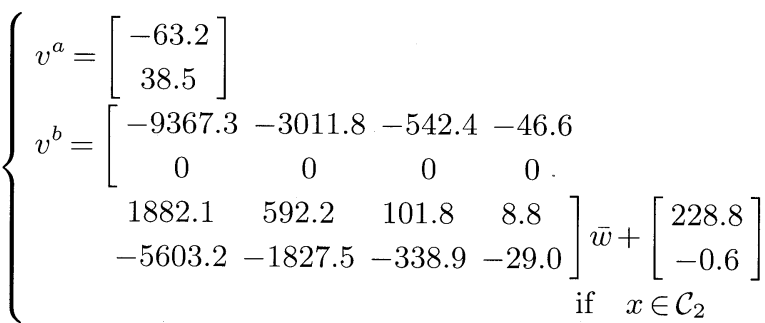

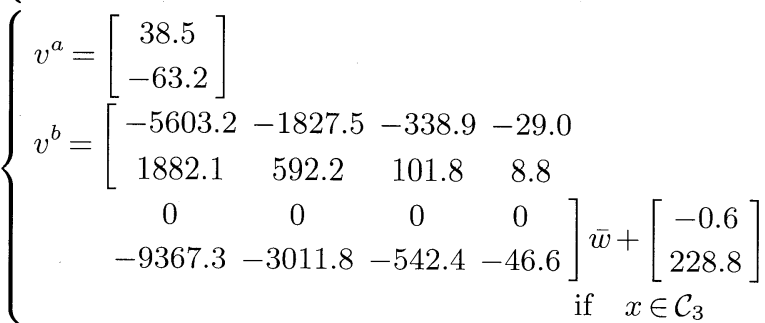

$$
\begin{aligned}
& \left\{\begin{aligned}
v^{a}= & {\left[\begin{array}{l}
-64.9 \\
-64.9
\end{array}\right] } \\
v^{b}= & {\left[\begin{array}{cccc}
-9367.3 & -3011.8 & -542.4 & -46.6 \\
1882.1 & 592.2 & 101.8 & 8.8 \\
1882.1 & 592.2 & 101.8 & 8.8 \\
& -9367.3-3011.8 & -542.4 & -46.6
\end{array}\right] \bar{w}+\left[\begin{array}{l}
221.3 \\
221.3
\end{array}\right] }
\end{aligned}\right.
\end{aligned}
$$

制御していない時と，(6)，(12)，(24) 式による制御 時のシミュレーション結果をFig. 4(a)，(b)にそれぞれ 示す.また，制御入力の時間応答を Fig. 4(c) に示した.

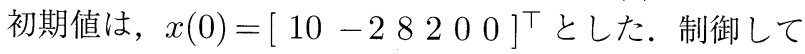
いない場合の Fig. 4(a)では着陸時の振る舞いが振動的 であるが（現実的には $\bar{x}_{1}, \bar{x}_{3}$ が負となる箇所ではス卜 ローク制限等を設ける必要があるが，ここでは単純な比 較のため, そのような処置はしていない), 制御した場合 の Fig. 4(b) では着陸時の振る舞いではチャタリングの ような現象もなく, 所期の目的を達成している。しかし， Fig. 4(c) に見られるように制御入力はかなり大きい。こ れは, 設計に狲いてシングルリアプノフ関数を使ってい ることにより，フィードバックゲインが大きくなってい ることによるものと推測される。より保守性の少ない制 御系設計法に改善することが今後の課題の一つである.

\section{5. おわりに}

本研究では，二つのスイッチを含むスイッチ駆動八イ ブリッドシステムに対して, well-posedness を保証しつ つ, かつ大域的に漸近安定化する手法を, well-posedness の観点からクラス $\mathrm{A}$ とクラス $\mathrm{B}$ に分けてそれぞれ議論し 


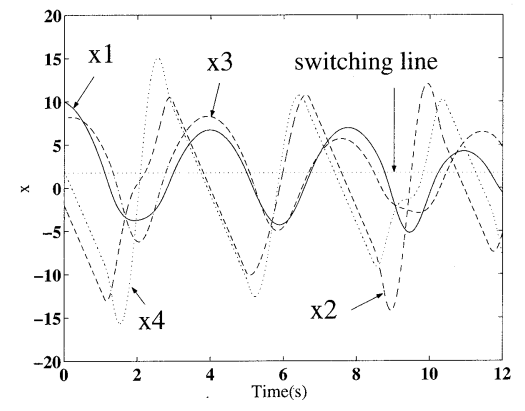

(a) Time response of the state in $u=0$

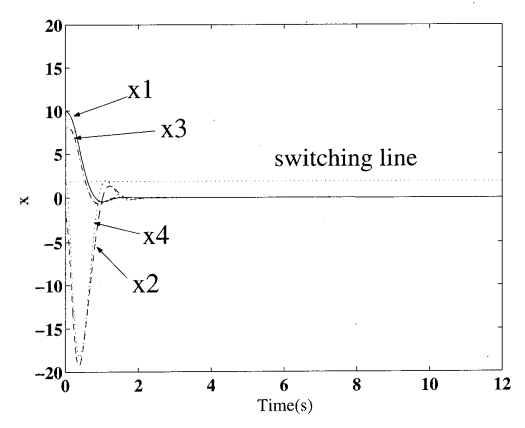

(b) Time response of the state in the proposed method

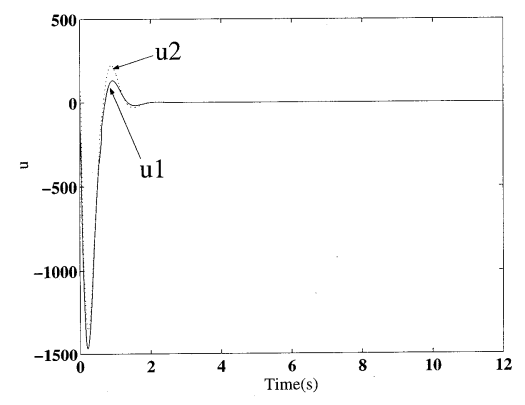

(c) Time response of the control input

Fig. 4 Simulation results of a landing system

た.クラス $\mathrm{A}$ の場合では, 切替えに関係するダイナミク スを連続システムに変換することにより，連続な線形シ ステムの制御論を使って安定化できることを示した.ク ラス B の場合では，動的コントローラを導入することに よって設計パラメータの自由度を増やすことにより LMI タイプの可解条件に安定化問題を帰着した.

\section{参考文献}

[1] M. Johansson and A. Rantzer: Computation of piecewise quadratic Lyapunov functions for hybrid systems; IEEE Trans. on Automatic Control, Vol. 43, No. 4, pp. 555-559 (1998)

[2] A. Hassibi and S. Boyd: Quadratic stabilization and control of piecewise-linear systems; Proc. of American Control Conference, pp. 3659-3664 (1998)

[3] J. Imura and A. J. van der Schaft: Characterization of well-posedness of piecewise linear systems;
IEEE Trans. on Automatic Control, Vol. 45, No. 9, pp. 1600-1619 (2000)

[4] J. Imura and A. J. van der Schaft: Well-posedness of a class of dynamically interconnected systems; Proc. of 38th IEEE Conference on Decision and Control, pp. 3031-3036 (1999)

[5] J. Imura: Feedback well-posedness and stbilizability of bimodal piecewise affine systems; CD-ROM Procedings of MTNS (2000)

[6] J. Imura: Classification and stabilizability of bimodal piecewise affine systems; Proc. of 39th IEEE Conference on Decision and Control, pp. 1409-1414 (2000)

[7] J. Imura: Well-posedness analysis of switch-driven hybrid systems; Proc. of American Control Conference, pp. 862-867 (2001)

[8] J. Imura, K. Shimizu and M. Saeki: Stabilization with well-posedness of a class of switch-driven hybrid systems (2001) (submitted to)

[9] A. Isidori: Nonlinear Control Systems, 3rd Edition, Springer (1995) 